\title{
Supplementation of Vitamin E Protects Chickens from Newcastle Disease Virus- Mediated Exacerbation of Intestinal Oxidative Stress and Tissue Damage
}

\author{
Zaib Ur Rehmana,b Luping Che ${ }^{\mathrm{a}}$ Shanhui Ren ${ }^{\mathrm{a}}$ Ying Liao ${ }^{\mathrm{a}} \quad$ Xusheng Qiu ${ }^{\mathrm{a}}$ \\ Shengqing Yu ${ }^{a}$ Yingjie Sun ${ }^{a} \quad$ Lei Tan ${ }^{a}$ Cuiping Song ${ }^{a} \quad$ Weiwei Liu ${ }^{a}$ \\ Zhuang Ding c Muhammad Munir ${ }^{\mathrm{c}}$ Venugopal Naire Chunchun Menga,f \\ Chan Ding ${ }^{a, f}$
}

aShanghai Veterinary Research Institute (SHVRI), Chinese Academy of Agricultural Sciences (CAAS), Shanghai, China, ${ }^{b}$ Department of Poultry Science, Faculty of Veterinary and Animal Sciences, PMAS Arid Agriculture University, Rawalpindi, Pakistan, 'Department of Preventive Veterinary Medicine, College of Veterinary Medicine, Jilin University, Changchun, China, ${ }^{~}$ Biomedical and Life Sciences, Lancaster

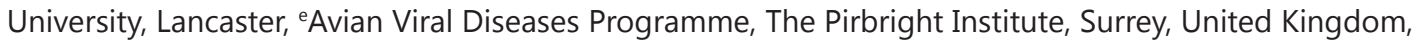
fJiangsu Co-Innovation Center for Prevention and Control of Important Animal Infectious Diseases and Zoonoses, Yangzhou University, Yangzhou, China

\section{Key Words}

Newcastle disease virus $•$ Oxidative stress $•$ Duodenum $•$ Jejunum $•$ Histopathology $•$ Vitamin E

\begin{abstract}
Background/Aims: Newcastle disease virus (NDV) causes a highly devastating and contagious disease in poultry, which is mainly attributed to extensive tissue damages in the digestive, respiratory and nervous systems. However, nature and dynamics of NDV-induced oxidative stresses in the intestine of chickens remain elusive. Methods: In this study, we examined the magnitude of intestinal oxidative stress and histopathological changes caused by the virulent NDV infection, and explored the protective roles of vitamin E (vit. E) in ameliorating these pathological changes. For these purposes, chickens were divided into four groups namely i) non supplemented and non-challenged (negative control, CON); ii) no supplementation of vit. E but challenged with ZJ1 (positive control, NS+CHA); iii) vit. E supplementation at the dose of $50 \mathrm{IU} /$ day/Kg body weight and ZJ1 challenge (VE50+CHA); and 4) vit. E supplementation at the dose of $100 \mathrm{IU} /$ day/Kg body weight and ZJ1 challenge (VE100+CHA). In all groups, we analyzed concentrations of glutathione (GSH), malondialdehyde (MDA), nitric oxide (NO), total antioxidant capacity (T-AOC), and activity of glutathione S-transferase (GST), superoxide dismutase (SOD), catalase (CAT) using biochemical methods. The virus loads were determined by quantitative RT-PCR and antibody titers by hemagglutination inhibition assays. We also examined the histopathological changes in the duodenal and jejunal mucosa at 3 and 5-day
\end{abstract}

Chan Ding

and Chunchun Meng 
post infection (dpi) with NDV. Results: A significant elevation in the NO level was observed in NDV challenged chickens compared to the CON chickens at 2 dpi. The MDA contents were significantly increased whereas GSH was significantly decreased in NDV-challenged chickens compared to control. Furthermore, activities of GST, CAT, SOD, as well as the TOAC were markedly decreased in challenged chickens in comparison with control. Virus copy numbers were higher in NDV infected NS+CHA group compared to other groups. Severe histopathological changes including inflammation, degeneration and broken villi were observed in the intestine of NDV challenged chickens. However, all these malfunctions of antioxidant system and pathological changes in the intestine were partially or completely reversed by the vit. E supplementation. Conclusions: Our results suggest that NDV infection causes oxidative stress and histopathological changes in the duodenum and jejunum of chickens, which can be partially or fully ameliorated by supplementation of vit. E. Additionally, these findings suggest that oxidative stress contributes to the intestinal damages in NDV infected chickens. These findings will help to understand the pathogenesis of NDV and further investigation of therapeutic agents for control of Newcastle disease.

(C) 2018 The Author(s)

Published by S. Karger AG, Basel

\section{Introduction}

Newcastle disease (ND) is a highly infectious viral disease of poultry, and is caused by virulent Newcastle disease virus (NDV). The endemicity and contagiousness of NDV are main attributors of heavy economic losses in the poultry industry, around the globe. NDV belongs to the Paramyxoviridae family and contains a negative-sense, non-segmented, and singlestranded RNA genome of $15 \mathrm{~kb}$ long [1,2]. The genome of NDV encodes nucleocapsid, fusion protein $(\mathrm{F})$, haemagglutinin-neuraminidase protein $(\mathrm{HN})$, matrix protein, phosphoprotein, and large polymerase protein. The $\mathrm{F}$ and $\mathrm{HN}$ proteins are mainly involved in the pathogenicity of the virus. After invasion, NDV use the cellular machinery for translation process and elicit the strong stress response [3].

The NDV's are classified into four pathotypes; asymptomatic enteric, lentogenic, mesogenic, and velogenic [4]. Mesogenic and velogenic strains are responsible for heavy mortality and systemic infections in the poultry. Velogenic strains of NDV may be neurotropic or viscerotropic depending upon their preference for the predilection site [1]. Neurotropic strains of NDV mainly cause neurological signs such as paresis and paralysis, whereas viscerotropic strains primarily cause visceral hemorrhage and diarrhea. NDV primarily replicate in the intestine of chicken [5] however its effect on the oxidative defence system of the intestinal tissue has not been studied.

Reactive oxygen (ROS) and nitrogen species (RNS) are produced in the cell as a result of metabolism, and play important roles in many physiological process of the body including immunomodulation, cell signaling, regulation of cytokines, hormone, transcription, apoptosis, ion transport and neuromodulation [6,7]. There is a dynamic redox balance in cells between the antioxidant and oxidant molecules and disturbance in the redox balance leads to oxidative stress which is detrimental to cells $[8,9]$. To prevent the body from oxidative stresses, antioxidant defense system intervenes which is comprised of two parts (1) enzymatic components including glutathione peroxidase, catalases (CAT), and superoxide dismutase (SOD), and (2) non-enzymatic components including vitamin E, vitamin C, glutathione, carotenoids, and flavonoids [7]. There are increasing number of reports demonstrating the positive correlation between oxidative stress and viral infections [10-13]. Controlled production of RS is involved in the killing of invading pathogens [7, 14], however oxidative stress enhances the viral replication and damages the cells.

Owing to their physiological importance and advantages for the cell integrity, the supply of exogenous nutrients including antioxidants may increase the cellular defense against oxidative stress caused by viral diseases. In this regard, alpha tocopherol is a plausible choice because of it's proven immunomodulatory, and antioxidant properties. It has been shown that supplementation of vitamin E prevents the oxidative stress caused by influenza 


\section{Cellular Physiology Cell Physiol Biochem 2018;47:1655-1666

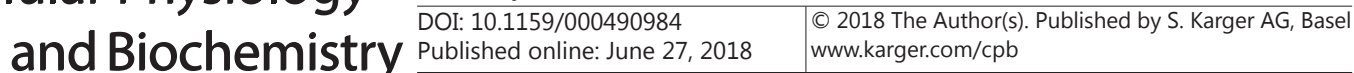 \\ Rehman et al.: Vitamin E Protects NDV Induced Oxidative Stress in Chicken}

viruses [15], and hepatitis C virus [16]. Recent studies conducted by Subbaiah et al. [17, 18], elucidate that the mesogenic NDV cause oxidative stress, protein oxidation and nitration in the liver and brain of chickens and vitamin $\mathrm{E}$ can mitigate these malfunctionings.

Adaptation of strict NDV vaccination schedule can significantly decrease ND outbreaks, and occurrence of atypical ND is common observed in poultry industry without inducing chicken mortalities [19]. These atypical outbreaks are common after second immunization at 26 to 35-day of age or during the laying periods without showing the typical intestinal pathology [20]. In these situations, decreased egg production [20-23] and growth rate [24, $25]$ are the major losses in vaccinated NDV flocks due to outbreak of atypical NDV. Nonuniform antibody titers in vaccinated flock may facilitate the slow growth of NDV in individual chickens instead of typical and deadly outbreak in the whole flock [20].

Here, we hypothesize that virulent NDV may cause pathological modifications in chickens with low antibody titers. We explored that NDV-induced oxidative stress and tissue damages in the intestines of chickens having lower limit of the protective antibody titers, which can be ameliorated by supplementation of vitamin $\mathrm{E}$.

\section{Materials and Methods}

\section{Reagents and virus}

Vitamin E was purchased from the Aladdine Biotechnology company (Shanghai, China). The glutathione (GSH), malondialdehyde (MDA), nitric oxide (NO), total antioxidant capacity (T-AOC), glutathione S-transferase (GST), superoxide dismutase (SOD), catalase (CAT) and protein detection kits were procured from Nanjing Jiancheng Biotechnology Research Institute (Nanjing, China).

Velogenic NDV isolate ZJ1 (Goose/China/ZJ1/2000; GB AF431744.3), was obtained from Professor Xiufan Liu at Yangzhou University, China. The stock of virus was prepared by growing through 10-day-old specific-pathogen-free (SPF) embryonated eggs and was subsequently stored at $-80^{\circ} \mathrm{C}$ until use.

\section{Animal management and experimental design}

Specific-pathogen-free (SPF) embryonated chicken eggs obtained from Merial (Merial Vital Laboratory Animal Technology Company, Beijing, China), were incubated at the laboratory facility of Shanghai Veterinary Research Institute (SHVRI), Chinese Academy of Agricultural Sciences (CAAS). One-day-old SPF chickens were orally vaccinated with LaSota vaccine and kept in isolators with ad libitum access to feed and water. Protocols used for the animal study were approved by SHVRI, CAAS Animal Care and Use Committee. Sixtysix SPF chickens were selected based on antibody titres at the age of 7 weeks and were divided into four groups, group 1 had 6 chickens and all other groups have 20 chickens each. The hemagglutination inhibition antibody titers of all selected chickens were 4-4.25 $\log _{2}$. Groups were treated as follow, non-supplemented, non-challenged control (CON), supplemented with $200 \mu \mathrm{l}$ of soybean oil and challenged with ZJ1 (NS+CHA), supplemented with vit. E at the dose of $50 \mathrm{IU} /$ day/Kg body weight and challenged with ZJ1 (VE50+CHA), and supplemented with vit. E at the dose of $100 \mathrm{IU} /$ day/Kg body weight and challenged with ZJ1 (VE100+CHA). Vitamin E was dissolved in $200 \mu \mathrm{l}$ of soybean oil for supplementation. The chickens in groups NS+CHA, VE50+CHA, and VE100+CHA were challenged by intramuscular route with ZJ1 at a dose of $10^{5.5}$ egg lethal dose $50 \%\left(E_{50}\right)$ at 7 days post supplementation.

\section{Detection of oxidative stress parameters}

At 2, 3, 4, and $5 \mathrm{dpi}$, four chickens from each challenged group were killed by an intravenous injection using pentobarbital sodium ( $40 \mathrm{mg} / \mathrm{kg}$ ), and intestine and the intestinal tract were removed. Chickens from the control group were humanely killed on $3 \mathrm{dpi}$. A segment of about 5- $6 \mathrm{~cm}$ was collected from the middle part of duodenum and jejunum, dissected and thoroughly cleaned with already cooled $\left(4^{\circ} \mathrm{C}\right)$ phosphate buffered saline (PBS). By using the glass slides, luminal face of cleaned duodenal and jejunum part of intestine was scraped and put into already marked and weighed aseptic tubes. These collected samples were immediately put in liquid nitrogen, transported to the laboratory, and stored at $-80^{\circ} \mathrm{C}$ until analyzed for oxidative stress parameters. Before analysis, mucosa was weighed and homogenized with PBS by using the Tissuelyser- 24 (Xin Jin Technology, Shanghai, China) at $20 \mathrm{~Hz}$ for 30 seconds, and instantly centrifuged 


\section{Cellular Physiology Cell Physiol Biochem 2018;47:1655-1666

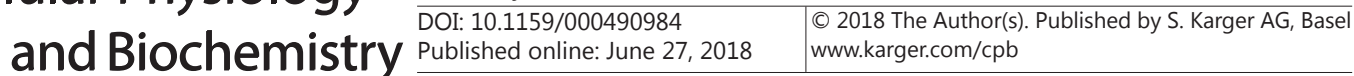 \\ Rehman et al.: Vitamin E Protects NDV Induced Oxidative Stress in Chicken}

at $3000 \mathrm{~g}$ at $4^{\circ} \mathrm{C}$ for 10 minutes. The pellet was discarded, and the supernatant was preserved in microtubes at $-80^{\circ} \mathrm{C}$ for future analysis.

After determining the amount of total protein in the supernatant of the mucosa homogenate by the Bradford method, the contents of GSH, MDA, NO, T-AOC, and activities of GST, SOD, and CAT were determined by biochemical methods following the instructions of the corresponding reagent kits. Catalog numbers of the above-mentioned reagent were GSH: Cat. No.: A006; MDA: Cat. No.: A003-2; NO: Cat. No.: A013-2; T-AOC. Cat. No.: A015-2; SOD. Cat. No.: A001-3; CAT. Cat. No.: A007-1; ALP. Cat. No.: A059-2.

\section{Detection of Viral loads in the intestine}

The total RNA was extracted from the intestinal samples using the TRIzol (Invitrogen, Carlsbad, CA, USA) following the manufacturer instructions. The quality of the RNA was examined by using NanoDrop ${ }^{\mathrm{TM}}$ 2000/2000c (Thermo Fisher Scientific Inc., Delaware, USA) for the ratio of $260 \mathrm{~nm}$ versus $280 \mathrm{~nm}$. Total RNA was reverse transcribed to cDNA using M-MLV reverse transcriptase (Promega, Madison, WI, USA) with the 6-nt random primer according to the manufacturer's instructions.

Real-time quantitative polymerase chain reaction (qRT-PCR) was performed to determine the expression of the ZJ1 M gene, and $\beta$-actin housekeeping gene was used for normalization using SYBR Premix Ex Taq reagents (Takara, Dalian, China) in the CFX96 real-time PCR detection (CFX96; Bio-Rad, USA) system. The primers used for viral M gene were: Forward: 5'-TACTTTGATTCTGCCCTCCCTT-3' and Reverse: 5' - TAAGCAGAGCATTGCGGAAGA- $3^{\prime}$, and for $\beta$-actin gene were: Forward: $5^{\prime}$ - ATTGTCCACCGCAAATGCTTC- ${ }^{\prime}$ and Reverse: 5'- AAATAAAGCCATGCCAATCTCGTC-3'. The expression of the target gene was normalized with the $\beta$-actin after ensuring the same amplification efficiency.

\section{Hemagglutination inhibition assay}

Hemagglutination inhibition (HI) test was performed by using the V-bottomed microwell plastic plates as described by the World Organization for Animal Health [26]. Serum samples were taken by jugular vein bleed at 3 and 5 dpi. For the test, the virus amount of ZJ1 was adjusted to 4 HA units. Highest serum dilution, which inhibited the hemagglutination was defined as titers and expressed as $\log _{2}$ of the reciprocal values.

\section{Histopathology of intestine}

At 3 and 5 dpi, duodenum and jejunum were collected from the four birds per treatment, wash with PBS and cut to a size approximately $0.5-1 \mathrm{~cm}$, placed in $10 \%$ formalin $(\mathrm{pH}=7.4)$ for $24 \mathrm{~h}$ at $25{ }^{\circ} \mathrm{C}$, and embedded in paraffin. These tissues were cut at $5 \mu \mathrm{m}$ section at three levels. These fixed tissues were stained with hematoxylin-eosin (H\&E) and mounted after the processes of dehydration, transparent, dipping wax, embedded, sectioned, and affixed. Then, the sections were placed under a microscope (Leica DM-2500, Germany) with a high-resolution digital camera to observe and record the relevant morphologies. Images were captured using the camera equipped with computer assisted morphometric system. Villus height of 15 villi per image was measured using the panoramic viewer (3DHISTECH Ltd., Hungary). Simultaneously, hematoxylin-eosin staining was applied to measure the numbers of intraepithelial lymphocytes (IEL) in different intestinal parts. The numbers of intraepithelial lymphocytes (IEL) in five different fields of an intestinal villus in each chicken were counted for statistical analysis [27].

Statistical analysis

All data were analysed by one-way analysis of variance with SPSS 18.0 software (SPSS Inc., Chicago, IL). Differences among means were compared using Duncan Multiple Range Test. The values were expressed as mean $(n=4)$, and $P<0.05$ was considered to indicate statistical significance.

\section{Results}

\section{Changes in the NO concentrations}

To determine if NDV is involved in the excessive production of NO, we infected the chickens with NDV, and plasma samples were collected at 2, 3, 4 and 5 dpi. As shown in Table 1 , there was a significant $(\mathrm{p}<0.01)$ increase in the NO concentration in duodenum and jejunum at $2 \mathrm{dpi}$. This increase in NO concentration in NS+CHA group was more than in 
CON, CHA+VE50, and CHA+VE100 groups $(p<0.05)$, highlighting the potential of NDV in inducing NO pathways.

\section{Changes of the MDA concentrations}

A non-significant ( $p>0.05)$ effect of treatments was observed on the MDA concentrations in both duodenal and jejunal mucosa on 2 dpi (Table 2). However, the MDA concentrations in duodenum and jejunum were markedly $(p<0.05)$ increased in ZJ1-challenged chickens compared to those of the control group from 3 to $5 \mathrm{dpi}$. As expected, the MDA concentration in NS+CHA group was higher $(\mathrm{p}<0.05)$ than CHA+VE50 and CHA+VE100 groups.

\section{Changes of the GSH concentrations}

The GSH concentration was decreased with the progression of disease especially in NS+CHA group compared to $\mathrm{CHA}+\mathrm{VE} 50$ and $\mathrm{CHA}+\mathrm{VE} 100$ groups. The GSH contents were significantly $(\mathrm{p}<0.01)$ decreased in ZJ1 challenged groups than control at 3 to $5 \mathrm{dpi}$. The GSH contents in CHA+VE100 group were markedly $(\mathrm{p}<0.05)$ decreased compared to $\mathrm{NS}+\mathrm{CHA}$ group (Table 3 ).

\section{Changes of the TAOC concentrations}

The TAOC of mucosa of duodenum and jejunum was decreased significantly $(p<0.05)$ by ZJ1 challenge and the TAOC decreased further on 5 dpi compared to 2 dpi (Table 4). However, decrease in total antioxidant capacity was significantly $(p<0.05)$ less in CHA+VE50 and $\mathrm{CHA}+\mathrm{VE100}$ groups compared to NS+CHA chickens.

\section{Changes of the CAT concentrations}

Catalase is an endogenous enzyme, which protects the cells from oxidative stress and a good indicator of free radical production. The activity of catalase was significantly $(p<0.05)$ decreased in challenged chickens when compared to control (Table 5). But, less decrease $(p<0.05)$ was found in vitamin $E$ supplemented groups.
Table 1. The concentrations of intestinal mucosa nitric oxide ( $\eta \mathrm{mol} / \mathrm{mg}$ protein) of chickens at 2-5 dpi. Values with different superscript letters in the same row are significantly different $(\mathrm{P}<0.05)$.

\begin{tabular}{cccccccc}
\hline & Dpi & CON & NS+CHA & VE50+CHA & VE100+CHA & SEM & P Value \\
\hline \multirow{4}{*}{ Duodenum } & 2 & $1.04^{\mathrm{b}}$ & $1.24^{\mathrm{a}}$ & $1.07^{\mathrm{b}}$ & $1.01^{\mathrm{b}}$ & 0.03 & 0.00 \\
& 3 & 1.04 & 1.13 & 1.06 & 1.05 & 0.01 & 0.13 \\
& 4 & 1.04 & 1.12 & 1.10 & 1.08 & 0.01 & 0.14 \\
& 5 & 1.04 & 1.12 & 1.05 & 1.07 & 0.01 & 0.21 \\
& 2 & $0.74^{\mathrm{b}}$ & $0.92^{\mathrm{a}}$ & $0.77^{\mathrm{b}}$ & $0.76^{\mathrm{b}}$ & 0.02 & 0.00 \\
& 3 & $0.74^{\mathrm{b}}$ & $0.84^{\mathrm{a}}$ & $0.72^{\mathrm{b}}$ & $0.77^{\mathrm{b}}$ & 0.01 & 0.00 \\
Jejunum & 4 & 0.74 & 0.82 & 0.79 & 0.76 & 0.01 & 0.17 \\
& 5 & 0.74 & 0.80 & 0.75 & 0.77 & 0.01 & 0.54 \\
\hline
\end{tabular}

Table 2. The concentrations of intestinal mucosa malondialdehyde ( $\eta \mathrm{mol} / \mathrm{mg}$ protein) of chickens at 2-5 dpi. Values with different superscript letters (a-c) in the same row are significantly different $(\mathrm{P}<0.05)$.

\begin{tabular}{cccccccc}
\hline & Dpi & CON & NS+CHA & VE50+CHA & VE100+CHA & SEM & P Value \\
\hline \multirow{5}{*}{ Duodenum } & 2 & 2.26 & 2.22 & 2.23 & 2.22 & 0.02 & 0.90 \\
& 3 & $2.26^{\mathrm{a}}$ & $2.44^{\mathrm{b}}$ & $2.30^{\mathrm{a}}$ & $2.28^{\mathrm{a}}$ & 0.03 & 0.05 \\
& 4 & $2.26^{\mathrm{c}}$ & $2.61^{\mathrm{a}}$ & $2.31^{\mathrm{c}}$ & $2.41^{\mathrm{b}}$ & 0.04 & 0.00 \\
& 5 & $2.26^{\mathrm{c}}$ & $2.73^{\mathrm{a}}$ & $2.42^{\mathrm{b}}$ & $2.36^{\mathrm{b}}$ & 0.05 & 0.00 \\
& 2 & 1.55 & 1.52 & 1.57 & 1.57 & 0.01 & 0.24 \\
& 3 & $1.55^{\mathrm{c}}$ & $1.75^{\mathrm{a}}$ & $1.63^{\mathrm{b}}$ & $1.57^{\mathrm{c}}$ & 0.02 & 0.00 \\
& 4 & $1.55^{\mathrm{c}}$ & $1.92^{\mathrm{a}}$ & $1.65^{\mathrm{b}}$ & $1.57^{\mathrm{c}}$ & 0.04 & 0.00 \\
& 5 & $1.55^{\mathrm{b}}$ & $2.34^{\mathrm{a}}$ & $1.74^{\mathrm{b}}$ & $1.66^{\mathrm{b}}$ & 0.08 & 0.00 \\
\hline
\end{tabular}

Table 3. The concentrations of intestinal mucosa glutathione ( $\mu \mathrm{mol} / \mathrm{mg}$ protein) of chickens at 2-5 dpi. Values with different superscript letters (a-c) in the same row are significantly different $(\mathrm{P}<0.05)$.

\begin{tabular}{cccccccc}
\hline & Dpi & CON & NS+CHA & VE50+CHA & VE100+CHA & SEM & P Value \\
\hline \multirow{4}{*}{ Duodenum } & 2 & 32.97 & 31.57 & 32.48 & 31.79 & 0.28 & 0.27 \\
& 3 & $32.97^{\mathrm{a}}$ & $24.95^{\mathrm{c}}$ & $28.35^{\mathrm{b}}$ & $28.43^{\mathrm{b}}$ & 0.85 & 0.00 \\
& 4 & $32.97^{\mathrm{a}}$ & $23.84^{\mathrm{c}}$ & $29.81^{\mathrm{ab}}$ & $27.37^{\mathrm{bc}}$ & 1.07 & 0.00 \\
& 5 & $32.97^{\mathrm{a}}$ & $24.58^{\mathrm{c}}$ & $27.40^{\mathrm{bc}}$ & $28.07^{\mathrm{b}}$ & 0.88 & 0.00 \\
& 2 & 20.97 & 20.73 & 20.46 & 20.47 & 0.15 & 0.64 \\
& 3 & $20.97^{\mathrm{a}}$ & $19.87^{\mathrm{a}}$ & $20.41^{\mathrm{a}}$ & $18.65^{\mathrm{b}}$ & 0.27 & 0.01 \\
& 4 & $20.97^{\mathrm{a}}$ & $16.93^{\mathrm{c}}$ & $18.57^{\mathrm{b}}$ & $19.31^{\mathrm{b}}$ & 0.40 & 0.00 \\
& 5 & $20.97^{\mathrm{a}}$ & $15.79^{\mathrm{c}}$ & $19.13^{\mathrm{b}}$ & $19.17^{\mathrm{b}}$ & 0.51 & 0.00 \\
\hline
\end{tabular}

\section{Changes of the SOD concentrations}

Compared to the control group, a significant $(p<0.05)$ decrease in the activity of SOD in both jejunal and duodenal mucosa of ZJ1 challenged chickens was observed (Table 6). 
SOD activity in vitamin E supplemented groups was significantly $(\mathrm{p}<0.05)$ less decreased when compared to NS+CHA.

\section{Changes of the GST concentrations}

NDV-challenge had markedly affected the activity of GST in both duodenum and jejunum. However, GST activity of NS+CHA group was decreased $(p<0.05)$ more than vitamin $\mathrm{E}$ supplemented and NDchallenged chickens (Table 7).

\section{Detection of viral load and antibody titer}

The qRT-PCR was performed to evaluate the differences in the viral replication in the intestine of chickens at 3 and $5 \mathrm{dpi}$. As shown in the Fig. 1A, viral copy numbers were significantly $(\mathrm{p}<0.05)$ higher in NDV challenged chickens compared to chickens from $\mathrm{CHA}+\mathrm{VE} 100$ group at both 3 and $5 \mathrm{dpi}$. As expected, the viral RNA levels were higher at 5 dpi than $3 \mathrm{dpi}$. An increase in antibody titer was observed in NDV challenged chickens and this increase was more significant $(p<0.05)$ in NS+CHA.

\section{Histopathological changes in intestine}

The H\&E stained sections of the duodenum and jejunum at $3 \mathrm{dpi}$ and $5 \mathrm{dpi}$ were presented in the Fig. 2. Significant changes were observed in the villus height, IEL and other morphological features of intestines. Villus height in the duodenum was significantly $(\mathrm{p}<0.01)$ less in NS+CHA group than the CON and CHA+VE100 at 3 and 5 dpi. Jejunal villus height in NS+CHA group was significantly less compared to CHA+VE50 at 5 dpi (Table 8). As presented in Table 8 , significant increase in the number of duodenal IEL was observed in NS+CHA group compared to CON, CHA+VE50 and CHA+VE100 groups at 3 and $5 \mathrm{dpi}$. Furthermore, the numbers of IEL in CHA+VE50 and CHA+VE100 groups were also significantly higher than CON at 3 and $5 \mathrm{dpi}$. The IELs in the jejunum were significantly affected by the NDV challenge. Numbers of IEL in jejunum at 3 dpi were higher in NS+CHA compared to CON, CHA+VE50, and CHA+VE100 groups. However, no significant difference was observed in IEL numbers in jejunum
Table 4. The concentrations of intestinal mucosa total antioxidant capacity (U/mg protein) of chickens at 2-5 dpi. Values with different superscript letters (a-d) in the same row are significantly different $(\mathrm{P}<0.05)$.

\begin{tabular}{cccccccc}
\hline & Dpi & CON & NS+CHA & VE50+CHA & VE100+CHA & SEM & P Value \\
\hline \multirow{4}{*}{ Duodenum } & 2 & 1.10 & 1.12 & 1.19 & 1.16 & 0.01 & 0.06 \\
& 3 & $1.10^{\mathrm{ab}}$ & $0.85^{\mathrm{c}}$ & $1.05^{\mathrm{b}}$ & $1.15^{\mathrm{a}}$ & 0.03 & 0.00 \\
& 4 & $1.10^{\mathrm{a}}$ & $0.79^{\mathrm{c}}$ & $1.00^{\mathrm{b}}$ & $0.98^{\mathrm{b}}$ & 0.03 & 0.00 \\
& 5 & $1.10^{\mathrm{a}}$ & $0.67^{\mathrm{d}}$ & $0.95^{\mathrm{b}}$ & $1.00^{\mathrm{c}}$ & 0.04 & 0.00 \\
& 2 & $1.04^{\mathrm{b}}$ & $1.24^{\mathrm{a}}$ & $1.28^{\mathrm{a}}$ & $0.99 \mathrm{~b}$ & 0.03 & 0.00 \\
& 3 & $1.04^{\mathrm{a}}$ & $0.90^{\mathrm{c}}$ & $0.97^{\mathrm{b}}$ & $0.97^{\mathrm{b}}$ & 0.01 & 0.00 \\
Jejunum & 4 & $1.04^{\mathrm{a}}$ & $0.73^{\mathrm{d}}$ & $0.88^{\mathrm{c}}$ & $0.95^{\mathrm{b}}$ & 0.03 & 0.00 \\
& 5 & $1.04^{\mathrm{a}}$ & $0.62^{\mathrm{c}}$ & $0.85^{\mathrm{b}}$ & $0.86^{\mathrm{b}}$ & 0.04 & 0.00 \\
& & & & & & & \\
\hline
\end{tabular}

Table 5. The concentrations of intestinal mucosa catalase (U/mg protein) of chickens at 2-5 dpi. Values with different superscript letters (a-d) in the same row are significantly different $(\mathrm{P}<0.05)$.

\begin{tabular}{cccccccc}
\hline & Dpi & CON & NS+CHA & VE50+CHA & VE100+CHA & SEM & P Value \\
& 2 & 9.18 & 9.07 & 9.08 & 9.07 & 0.02 & 0.29 \\
& 3 & $9.18^{\mathrm{a}}$ & $6.65^{\mathrm{d}}$ & $8.11^{\mathrm{c}}$ & $8.51^{\mathrm{b}}$ & 0.24 & 0.00 \\
Duodenum & 4 & $9.18^{\mathrm{a}}$ & $5.55^{\mathrm{c}}$ & $7.91^{\mathrm{b}}$ & $7.68^{\mathrm{b}}$ & 0.34 & 0.00 \\
& 5 & $9.18^{\mathrm{a}}$ & $4.92^{\mathrm{d}}$ & $7.64^{\mathrm{b}}$ & $8.14^{\mathrm{c}}$ & 0.41 & 0.00 \\
& 5 & 6.58 & 6.60 & 6.54 & 6.57 & 0.01 & 0.23 \\
& 2 & & & & \\
Jejunum & 3 & $6.58^{\mathrm{b}}$ & $6.14^{\mathrm{a}}$ & $6.54^{\mathrm{b}}$ & $6.54^{\mathrm{b}}$ & 0.05 & 0.00 \\
& 4 & $6.58^{\mathrm{a}}$ & $5.33^{\mathrm{d}}$ & $6.08^{\mathrm{c}}$ & $6.43^{\mathrm{b}}$ & 0.13 & 0.00 \\
& 5 & $6.58^{\mathrm{a}}$ & $4.77^{\mathrm{c}}$ & $5.95^{\mathrm{b}}$ & $5.92^{\mathrm{b}}$ & 0.17 & 0.00 \\
\hline
\end{tabular}

Table 6. The concentrations of intestinal mucosa superoxide dismutase (U/mg protein) of chickens at 2-5 dpi. Values with different superscript letters (a-c) in the same row are significantly different ( $\mathrm{P}$ $<0.05$ ).

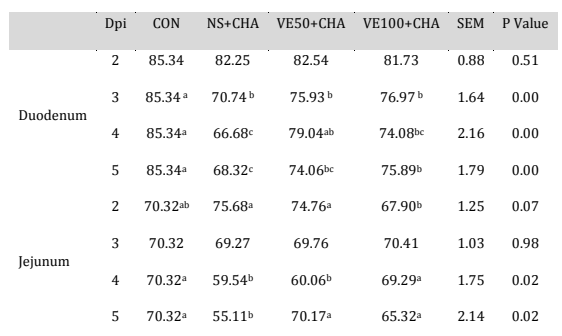

Fig. 1. Determination of NDV loads and Hemagglutination inhibition (HI) titers. A: NDV loads. Samples were collected at 3 and $5 \mathrm{dpi}$, and $\mathrm{M}$ gene was targeted to quantify the NDV replication in the intestine of tested chickens. B: NDV HI antibody titers. Sera from all the tested chickens were collected at 3 and $5 \mathrm{dpi}$ and HI titers were determined. Bars with a common superscript letter are not significantly different $(\mathrm{p} \leq 0.05)$.

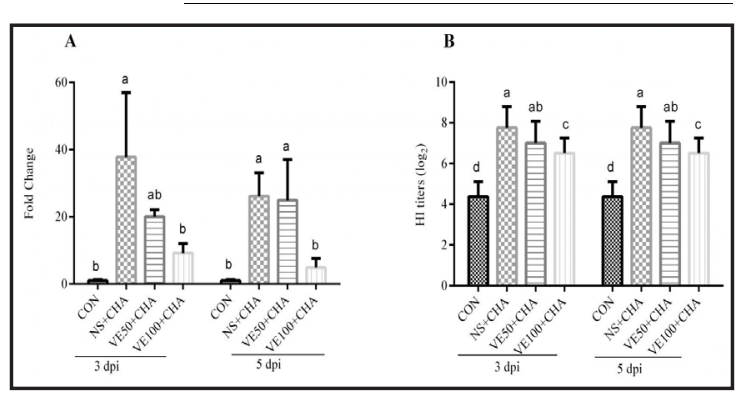




\section{Cellular Physiology Cell Physiol Biochem 2018;47:1655-1666 \begin{tabular}{l|l} 
DOI: 10.1159/000490984 & and Biochemistry 2018 The Author(s). Published by S. Karger AG, Basel \\
wublished online: June 27, 2018 & $\begin{array}{l}\text { wwrger.com/cpb } \\
\text { and }\end{array}$
\end{tabular}

Fig. 2. Photomicrograph of NDV induced histopathological changes and vitamin E provided protective effects in chicken duodenum and Jejunum. Panels marked with upper case letters (A to D) and (E to F) showed the histopathological results in the duodenum of chickens in $\mathrm{CON}$, NS+CHA, VE50+CHA and VE100+CHA groups, at 3 and 5 dpi respectively. Panels marked with lower case letters (a to d) and (e to f) showed the histopathological results in the jejunum of chicken in CON, NS+CHA, VE50+CHA and VE100+CHA groups, at 3 and 5 dpi respectively.

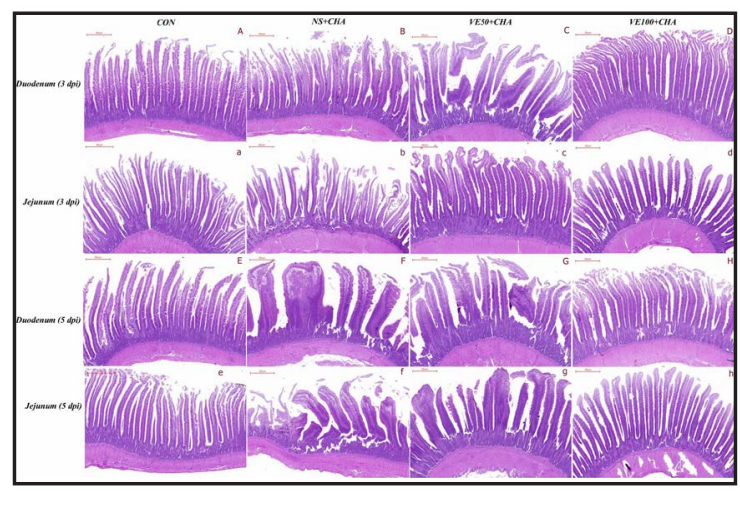
No histopathological change was observed in the intestine of control chickens. Severe histopathological changes including inflammation, degeneration, and broken villi, as well as irregular distribution of nuclei in the cells were observed in the NS+CHA group. NDV induced pathological changes were partially ameliorated by supplementation of vit. E at the dose of 50 IU/ day/Kg body weight in the VE50+CHA group, and were almost totally ameliorated by supplementation of vit. $\mathrm{E}$ at the dose of $100 \mathrm{IU} /$ day/Kg body weight in the VE100+CHA group.

at 5 dpi. In the NDV infected groups mild duodenitis and jejunitis was observed, and it was more in NS+CHA group compared to $\mathrm{CON}$ and $\mathrm{CHA}+\mathrm{VE} 100$. In addition, inflammation, degeneration, and necrosis of villi in duodenum and jejunum were observed and these were more pronounced in the NS+CHA group, compared to CON (Fig. 2).

\section{Discussion}

ND causes heavy economic losses to the poultry industry by damaging the respiratory, digestive and nervous systems. Even in the vaccinated chickens, NDV can replicate and cause atypical disease leading to decrease in the growth rate and egg production [20, 23, 25]. Despite the extensive research on NDV-caused damages in chickens, studies explaining the involvement of oxidative stress in intestine of poultry are lacking. Given the replication of NDV in the digestive tract, understand the level and magnitude of oxidative stress in the intestine are imperative. Many RNA viruses can induce oxidative stress to enhance viral replication and cell death $[7,11,28,29]$. Oxidative stress is due to dysregulation of cellular metabolism, resulting in excessive productions of ROS and RNS, which disturbs the cellular antioxidant enzymes and cause the cellular injuries [30]. Harmful effects of the oxidative stress in the cells/body are nullified by the enzymatic (CAT, SOD, GST, glutathione peroxidase) and nonenzymatic (GSH, vit. E, A, D, C) antioxidant factors. Recently, Subbaiah et al $[17,18]$. have
Table 7. The concentrations of intestinal mucosa glutathione S-transferase (U/mg protein) of chickens at 2-5 dpi. Values with different superscript letters in the same row are significantly different $(\mathrm{P}<0.05)$.

\begin{tabular}{lccccccc}
\hline & Dpi & CON & NS+CHA & VE50+CHA & VE100+CHA & SEM & P Value \\
\hline \multirow{4}{*}{ Duodenum } & 2 & $28.24^{\mathrm{ab}}$ & $26.00^{\mathrm{b}}$ & $27.26^{\mathrm{ab}}$ & $27.05^{\mathrm{a}}$ & 0.29 & 0.03 \\
& 3 & $28.24^{\mathrm{a}}$ & $24.37^{\mathrm{b}}$ & $25.26^{\mathrm{b}}$ & $27.05^{\mathrm{ab}}$ & 0.56 & 0.04 \\
& 4 & $28.24^{\mathrm{a}}$ & $18.88^{\mathrm{b}}$ & $26.44^{\mathrm{a}}$ & $26.49^{\mathrm{a}}$ & 0.98 & 0.00 \\
& 5 & $28.24^{\mathrm{a}}$ & $17.64^{\mathrm{c}}$ & $25.70^{\mathrm{b}}$ & $26.76^{\mathrm{b}}$ & 1.08 & 0.00 \\
& 2 & 23.62 & 23.89 & 22.69 & 23.82 & 0.25 & 0.30 \\
& 3 & $23.62^{\mathrm{a}}$ & $21.53^{\mathrm{b}}$ & $22.95^{\mathrm{a}}$ & $22.84^{\mathrm{a}}$ & 0.26 & 0.02 \\
& 4 & $23.62^{\mathrm{a}}$ & $19.80^{\mathrm{b}}$ & $21.04^{\mathrm{ab}}$ & $22.74^{\mathrm{ab}}$ & 0.56 & 0.05 \\
& 5 & $23.62^{\mathrm{a}}$ & $14.74^{\mathrm{b}}$ & $22.11^{\mathrm{a}}$ & $22.29^{\mathrm{a}}$ & 0.94 & 0.00 \\
\hline
\end{tabular}

Table 8. Intestinal histomorphology of chickens infected with NDV and supplemented with vitamin $\mathrm{E}$ at 3 and $5 \mathrm{dpi}$. Values with different superscript letters $(\mathrm{a}-\mathrm{c})$ in the same row are significantly different $(\mathrm{P}<0.05)$.

\begin{tabular}{ccccccccc} 
& Dpi & Parameters & CON & NS+CHA & VE50+CHA & VE100+CHA & SEM & P Value \\
\hline \multirow{4}{*}{ Duodenum } & 3 & Villus Height & $1071.8^{\mathrm{a}}$ & $858.6^{\mathrm{b}}$ & $946.6^{\mathrm{ab}}$ & $1009.7^{\mathrm{a}}$ & 23.62 & 0.01 \\
& 3 & IEL & $25.9^{\mathrm{d}}$ & $33.2^{\mathrm{a}}$ & $30.6^{\mathrm{b}}$ & $28.5^{\mathrm{c}}$ & 0.54 & 0.00 \\
& 5 & Villus Height & $1149.3^{\mathrm{b}}$ & $883.8^{\mathrm{a}}$ & $926.2^{\mathrm{b}}$ & $987.9^{\mathrm{b}}$ & 23.17 & 0.00 \\
& 5 & IEL & $25.9^{\mathrm{c}}$ & $32.8^{\mathrm{a}}$ & $29.7^{\mathrm{b}}$ & $27.3^{\mathrm{c}}$ & 0.53 & 0.00 \\
& 3 & Villus Height & $950.2^{\mathrm{b}}$ & $872.7^{\mathrm{b}}$ & $948.6^{\mathrm{b}}$ & $1098.8^{\mathrm{a}}$ & 21.65 & 0.00 \\
& 3 & IEL & $23.6^{\mathrm{b}}$ & $26.2^{\mathrm{a}}$ & $24.3^{\mathrm{b}}$ & $24.3^{\mathrm{b}}$ & 0.28 & 0.00 \\
Jejunum & 5 & Villus Height & $930^{\mathrm{ab}}$ & $871^{\mathrm{b}}$ & $981.9^{\mathrm{a}}$ & $902^{\mathrm{b}}$ & 14.24 & 0.04 \\
& 5 & IEL & 23.6 & 21.9 & $23.2^{2}$ & 22.3 & 0.60 & 0.75
\end{tabular}




\section{Cellular Physiology Cell Physiol Biochem 2018;47:1655-1666 \\ \begin{tabular}{l|l|l} 
DOI: 10.1159/000490984 & O 2018 The Author(s). Published by S. Karger AG, Basel \\
www.karger.com/cpb
\end{tabular} \\ Rehman et al.: Vitamin E Protects NDV Induced Oxidative Stress in Chicken}

found that mesogenic NDV caused the oxidative stress in the liver, brain and heart of chickens. However, the major complication in the field situation is the simultaneous circulation of virulent NDV and atypical NDV, which affect the intestines leading to stunted growth. In the present study, effects of NDV infection and vitamin E supplementation were observed on the mucosal oxidative stress and histopathology. The results demonstrate that NDV infection activates the free radical production accompanied by the decrease in activities of antioxidant enzymes and natural cellular antioxidants like GSH in intestine of chickens. Furthermore, we describe that, supplementation of vitamin E partially prevented the oxidative stress and tissue damage in NDV challenged chickens.

The NO serves as an intercellular and intracellular messenger and plays vital role in many physiological and pathological conditions [31]. The NO is beneficial during normal homeostasis and mild to moderate diseases, leads to increased immune response as well as cellular migration across epithelial barriers [32] and has mutagenic effects at higher levels. We observed a higher level of NO in intestinal mucosa in NDV challenged groups compared to control. Our results are in agreement with the Ahmed, et al [33]. and Lam, et al [34]. which demonstrate the higher production of NO from chicken peripheral blood mononuclear cells and heterophils respectively. Similar result of higher levels of NO are associated in lung injury in influenza infected mice [35]. These higher levels of NO may be involved in the damage to intestinal barrier function and cell death because it can form peroxynitrite by reacting with superoxide [36], which on decomposition produce more toxic free radicals leading to damage to lipid membranes, proteins and nucleic acids [37]. The MDA is an indicator of lipid peroxidation, and can cause the damage to cell membrane, DNA and proteins leading to death. In this study, higher levels of MDA had been found in the duodenum and jejunum of NDV challenged chickens and this was less in vit. E supplemented chickens. Our results are in good agreement with the previous studies demonstrating the higher levels of MDA in brain $[38,39]$ and bursa [40] of NDV infected chickens. These higher production levels of NO and lipid peroxidants may lead increased levels of RNS and ROS which play a vital role in NDV infection. The antioxidant capacities of all the known and unknow antioxidants present in body fluids is named as TAOC whereas, the individual cellular antioxidants include GSH, CAT, SOD, GST, etc. Results of the present study demonstrate the decrease in TAOC in the intestinal mucosa of NDV challenged chickens. Whereas, supplementation of vit. E partially reduces the changes in TAOC in NDV infected chickens.

The GSH is the cysteine-containing tripeptide, a major cellular non-enzymatic antioxidant component. Glutathione S-transferases (GSTs) are a family of Phase II detoxification enzymes that function to protect cellular macromolecules from attack by reactive electrophiles. Particularly, GST catalyses the conjugation of GSH to a variety of endogenous and exogenous electrophilic compounds [41]. The SOD is an important enzyme involved in the oxidative stress and provides protection against lipid peroxidation [42]. Catalase is an iron containing enzyme which catalyses the breakdown of hydrogen peroxide, a harmful agent for the cells. In the present study, decreases in GSH level and activities of CAT, SOD, GST were observed in NDV infected groups. Supplementation of chickens with vit. E significantly prevented the oxidative stress induced by NDV challenge. Our results are consistent with several reported studies, in which authors had demonstrated an increase in oxidative stress by infection of different RNA viruses like influenza virus [11, 12, 43], hepatitis virus [44, 45], human immunodeficiency virus [46], and dengue virus [47]. Infection of chickens with mesogenic NDV also showed the comparable results of decreased activities of CAT, GST and increased levels of MDA [17]. The vit. E supplementation has shown to increase the activity of antioxidant enzymes [48], which is also in accordance with the current study. These results indicate that vit. E supplementation in NDV infected chickens partially prevents the oxidative stress by maintaining the levels of GSH and activities of CAT, GST and SOD.

An increase in antibody titer was observed in all NDV challenge groups, suggesting that vit. E supplementation cannot prevent the replication of virus in chickens. However, less viral loads were detected in vit. E supplemented chickens. This might be due to immunomodulating effects of vit. E, as it is well known that it affects the proliferation, 
interleukin 2 (IL-2) production ability of naïve T cells, and decrease the production of prostaglandin E2 (T-cell suppressive factor) from macrophages [49-51]. The IL-2 is involved in the lymphocyte proliferation, natural killer cells activation, and clearance of intracellular pathogens, promotion of Th1 immune response and cell mediated immunity $[49,51]$. It has been studied that recombinant ZJ1 expressing the IL-2 results in decreased severity of hemorrhagic lesions in the intestine, lymphoid depletion, necrosis in lymphoid organ as well as magnitude of viral load in the lymphoid organs [52]. This increased stimulation capacity of vit. E supplementation on IL-2 might be involved in the decreased viral load in the intestine.

Other than oxidative stress parameters, we additionally examined the intestinal histomorphology. Decrease in villus height was observed in NDV infected chickens, which may be the result of histopathological changes such as degeneration and necrosis of intestinal villi. The most severe pathological changes of degeneration and necrosis were observed at the tip of villi in NDV challenged, non-supplemented chickens. This information is supported by increased numbers of IEL, and secretory IgA, and decreased goblet cells in the duodenum and jejunum of NDV-infected chickens [53]. We assumed that less severe pathological changes in vitamin E supplemented groups might be due to its protective effects in the intestinal barrier function [54] or enhanced immune responses [49].

In conclusion, NDV infection of chickens induces oxidative stress in the duodenum and jejunum and this oxidative stress is due to higher levels of NO, MDA, and decreased concentrations of GSH in the intestinal mucosa. Furthermore, decreased activities of the antioxidant enzymes such as CAT, GST, and SOD along with histological alterations of intestine were observed in NDV-challenged chickens. We also observed that vitamin E supplementation minimizes all such changes in the antioxidant defense system and decrease the virus load and histopathological changes in the intestine. Therefore, we summarized that vitamin E supplementation could be used to ameliorate NDV induced intestinal oxidative stress and damage, which may help to improve the productivity of flocks. Further studies are needed to target the underlying molecular pathways in NDV infection, which are on the way in our laboratory.

\section{Abbreviations}

Dpi (days post infection); CON (non-supplemented non-challenged control); NS+CHA (non-supplemented + challenged with ZJ1); VE50+CHA (vitamin (E50 IU/day/ Kg body weight + challenged with ZJ1); VE100+CHA (vitamin (E100 IU/day/ Kg body weight + challenged with ZJ1); SEM (pooled standard error of mean).

\section{Acknowledgements}

This work was supported by the National Key Research and Development Program of China grant number 2018YFD0500100 (to CD), 2016YFD0501603 (to XQ) and National Natural Science Foundation of China Grant number 31530074 (to CD).

\section{Disclosure Statement}

The authors declare to have no competing interests.

\section{References}




\section{Cellular Physiology Cell Physiol Biochem 2018;47:1655-1666 and Biochemistry Published online: June 27, $2018 \quad \begin{aligned} & \text { DOI: } 2018 \text { The Author(s). Published by S. Karger AG, Basel } \\ & \text { www.karger.com/cpb }\end{aligned}$ \\ Rehman et al.: Vitamin E Protects NDV Induced Oxidative Stress in Chicken}

2 Meng C, Qiu X, Yu S, Li C, Sun Y, Chen Z, Liu K, Zhang X, Tan L, Song C, Liu G, Ding C: Evolution of newcastle disease virus quasispecies diversity and enhanced virulence after passage through chicken air sacs. J Virol 2016;90:2052-2063.

3 Sun Y, Dong L, Yu S, Wang X, Zheng H, Zhang P, Meng C, Zhan Y, Tan L, Song C, Qiu X, Wang G, Liao Y, Ding C: Newcastle disease virus induces stable formation of bona fide stress granules to facilitate viral replication through manipulating host protein translation. FASEB J 2017;31:1337-1353.

$\checkmark 4$ Cattoli G, Susta L, Terregino C, Brown C: Newcastle disease: a review of field recognition and current methods of laboratory detection. J Vet Diagn Invest 2011;23:637-656.

-5 Cheville NF, Beard CW, Heminover JA: Comparative cytopathology of Newcastle disease virus. Use of ferritin-labeled antibody on allantoic and intestinal epithelium. Vet Pathol 1972;9:38-52.

6 Gloire G, Legrand-Poels S, Piette J: NF-kappaB activation by reactive oxygen species: fifteen years later. Biochem Pharmacol 2006;72:1493-1505.

7 Reshi ML, Su YC, Hong JR: RNA Viruses: ROS-Mediated Cell Death. Int J Cell Biol 2014;2014:467452.

8 Bhattacharyya A, Chattopadhyay R, Mitra S, Crowe SE: Oxidative stress: an essential factor in the pathogenesis of gastrointestinal mucosal diseases. Physiol Rev 2014;94:329-354.

-9 Lin MT, Beal MF: Mitochondrial dysfunction and oxidative stress in neurodegenerative diseases. Nature 2006;443:787-795.

10 Zhang Y, Wang Z, Chen H, Chen Z, Tian Y: Antioxidants: potential antiviral agents for Japanese encephalitis virus infection. Int J Infect Dis 2014;24:30-36.

11 Qi X, Zhang H, Wang Q, Wang J: The NS1 protein of avian influenza virus H9N2 induces oxidative-stressmediated chicken oviduct epithelial cells apoptosis. J Gen Virol 2016;97:3183-3192.

-12 Sgarbanti R, Amatore D, Celestino I, Marcocci ME, Fraternale A, Ciriolo MR, Magnani M, Saladino R, Garaci E, Palamara AT, Nencioni L: Intracellular redox state as target for anti-influenza therapy: Are antioxidants always effective? Curr Top Med Chem 2014;14:2529-2541.

13 Vlahos R, Stambas J, Bozinovski S, Broughton BR, Drummond GR, Selemidis S: Inhibition of Nox2 oxidase activity ameliorates influenza A virus-induced lung inflammation. PLoS Pathog 2011;7:e1001271.

14 Hennet T, Peterhans E, Stocker R: Alterations in antioxidant defences in lung and liver of mice infected with influenza A virus. J Gen Virol 1992;73:39-46.

15 Tantcheva LP, Stoeva ES, Galabov AS, Braykova AA, Savov VM, Mileva MM: Effect of vitamin E and vitamin C combination on experimental influenza virus infection. Methods Find Exp Clin Pharmacol 2003;25:259264.

16 Lozano-Sepulveda SA, Bryan-Marrugo OL, Cordova-Fletes C, Gutierrez-Ruiz MC, Rivas-Estilla AM: Oxidative stress modulation in hepatitis C virus infected cells. World J Hepatol 2015;7:2880-2889.

17 Subbaiah KC, Raniprameela D, Visweswari G, Rajendra W, Lokanatha V: Perturbations in the antioxidant metabolism during Newcastle disease virus (NDV) infection in chicken : protective role of vitamin E. Naturwissenschaften 2011;98:1019-1026.

18 Subbaiah KC, Valluru L, Rajendra W, Ramamurthy C, Thirunavukkarusu C, Subramanyam R: Newcastle disease virus (NDV) induces protein oxidation and nitration in brain and liver of chicken: Ameliorative effect of vitamin E. Int J Biochem Cell Biol 2015;64:97-106.

19 Yu L, Wang Z, Jiang Y, Chang L, Kwang J: Characterization of newly emerging Newcastle disease virus isolates from the People's Republic of China and Taiwan. J Clin Microbiol 2001;39:3512-3519.

20 Umali DV, Ito H, Shirota K, Ito T, Katoh H: Atypical velogenic Newcastle disease in a commercial layer flock in Japan. Poult Sci 2015;94:890-897.

21 Cho SH, Kwon HJ, Kim TE, Kim JH, Yoo HS, Kim SJ: Variation of a newcastle disease virus hemagglutininneuraminidase linear epitope. J Clin Microbiol 2008;46:1541-1544.

22 Kwon H: Molecular characterization of fusion and hemagglutininneuraminidase genes of Newcastle disease virus, Ph. D. thesis. Seoul National University, Seoul, Korea, 2000,

23 Raghul J, Raj GD, Manohar BM, Balachandran C: Protection of the reproductive tract of young chicks by Newcastle disease virus-induced haemagglutinationinhibition antibodies. Vet Res Commun 2006;30:95102.

24 USDAAPHIS: Exotic Newcastle disease: a new form of a familiar poultry disease. U.S. Dept. of Agriculture, Animal and Plant Health Inspection Service, U.S. Govt. Print. Off., 1975.

25 van Boven M, Bouma A, Fabri TH, Katsma E, Hartog L, Koch G: Herd immunity to Newcastle disease virus in poultry by vaccination. Avian Pathol 2008;37:1-5. 


\section{Cellular Physiology Cell Physiol Biochem 2018;47:1655-1666 $\begin{array}{lll}\text { DOI: 10.1159/000490984 } & \text { Ond Biochemistry } 2018 \text { The Author(s). Published by S. Karger AG, Basel } \\ \text { Published online: June 27, } 2018 & \begin{array}{l}\text { www.karger.com/cpb } \\$\cline { 2 - 3 }\end{array}\end{array}}

Rehman et al.: Vitamin E Protects NDV Induced Oxidative Stress in Chicken

26 OIE.: Newcastle disease (infection with Newcastle disease virus); Manual of Diagnostic Tests and Vaccines for Terrestrial Animals. Paris, World Organisation for Animal Health, 2012, pp 555-574.

27 Wang D, Zhou X, She R, Xiong J, Sun Q, Peng K, Liu L, Liu Y: Impaired intestinal mucosal immunity in specific-pathogen-free chickens after infection with very virulent infectious bursal disease virus. Poult Sci 2009;88:1623-1628.

28 Fuchs J, Ochsendorf F, Schofer H, Milbradt R, Rubsamen-Waigmann H: Oxidative imbalance in HIV infected patients. Med Hypotheses 1991;36:60-64.

-29 Okuda M, Li K, Beard MR, Showalter LA, Scholle F, Lemon SM, Weinman SA: Mitochondrial injury, oxidative stress, and antioxidant gene expression are induced by hepatitis $\mathrm{C}$ virus core protein. Gastroenterology 2002;122:366-375.

-30 Abba Y, Hassim H, Hamzah H, Ibrahim OE, Mohd Lila MA, Noordin MM: Pathological vicissitudes and oxidative stress enzyme responses in mice experimentally infected with reptarenavirus (isolate UPM/ MY01). Microb Pathog 2017;104:17-27.

-31 Tuteja N, Chandra M, Tuteja R, Misra MK: Nitric Oxide as a Unique Bioactive Signaling Messenger in Physiology and Pathophysiology. J Biomed Biotechnol 2004;2004:227-237.

32 Vallance BA, Deng W, De Grado M, Chan C, Jacobson K, Finlay BB: Modulation of inducible nitric oxide synthase expression by the attaching and effacing bacterial pathogen Citrobacter rodentium in infected mice. Infect Immun 2002; 70:6424-6435.

-33 Ahmed KA, Saxena VK, Ara A, Singh KB, Sundaresan NR, Saxena M, Rasool TJ: Immune response to Newcastle disease virus in chicken lines divergently selected for cutaneous hypersensitivity. Int J Immunogenet 2007;34:445-455.

-34 Lam KM, Kabbur MB, Eiserich JP: Newcastle disease virus-induced functional impairments and biochemical changes in chicken heterophils. Vet Immunol Immunopathol 1996;53:313-327.

-35 Perrone LA, Belser JA, Wadford DA, Katz JM, Tumpey TM: Inducible nitric oxide contributes to viral pathogenesis following highly pathogenic influenza virus infection in mice. J Infect Dis 2013;207:15761584.

-36 Robinson EK, Kennison SD, Suliburk JW, Mercer DW: Rat gastric injury after lipopolysaccharide: role of inducible nitric oxide synthase. Surgery 2005;138:523-529.

37 Zimiani K, Guarnier FA, Miranda HC, Watanabe MA, Cecchini R: Nitric oxide mediated oxidative stress injury in rat skeletal muscle subjected to ischemia/reperfusion as evaluated by chemiluminescence. Nitric Oxide 2005;13:196-203.

-38 Subbaiah KCV, Wudayagiri R, Valluru L: Newcastle disease virus (NDV) modulates pro/antioxidant status in different brain regions of chicken. Free Radic Antioxi 2013;3:81-86.

-39 Rehman Z, Qiu X, Sun Y, Liao Y, Tan L, Song C, Yu S, Ding Z, Munir M, Nair V, Meng C, Ding C: Vitamin E supplementation ameliorates newcastle disease virus-induced oxidative stress and alleviates tissue damage in the brains of chickens. Viruses 2018;10:173.

-40 Kristeen-Teo YW, Yeap SK, Tan SW, Omar AR, Ideris A, Tan SG, Alitheen NB: The effects of different velogenic NDV infections on the chicken bursa of Fabricius. BMC Vet Res 2017;13:151.

41 Townsend DM, Tew KD: The role of glutathione-S-transferase in anti-cancer drug resistance. Oncogene 2003;22:7369-7375.

-42 Surai PF: Antioxidant Systems in Poultry Biology: Superoxide Dismutase. J Anim Res Nutr 2015;1:8.

43 Wang J, Chen Y, Gao N, Wang Y, Tian Y, Wu J, Zhang J, Zhu J, Fan D, An J: Inhibitory effect of glutathione on oxidative liver injury induced by dengue virus serotype 2 infections in mice. PLoS One 2013;8:e55407.

44 Chen Y, Zeng L, Lu Y, Yang Y, Xu M, Wang Y, Liu J: Treatment effect of a flavonoid prescription on duck virus hepatitis by its hepatoprotective and antioxidative ability. Pharm Biol 2017;55:198-205.

45 Yu JS, Chen WC, Tseng CK, Lin CK, Hsu YC, Chen YH, Lee JC: Sulforaphane Suppresses Hepatitis C Virus Replication by Up-Regulating Heme Oxygenase-1 Expression through PI3K/Nrf2 Pathway. PLoS One 2016;11:e0152236.

46 Ivanov AV, Valuev-Elliston VT, Ivanova ON, Kochetkov SN, Starodubova ES, Bartosch B, Isaguliants MG: Oxidative Stress during HIV Infection: Mechanisms and Consequences. Oxid Med Cell Longev 2016;2016:8910396.

47 Olagnier D, Peri S, Steel C, van Montfoort N, Chiang C, Beljanski V, Slifker M, He Z, Nichols CN, Lin R, Balachandran S, Hiscott J: Cellular oxidative stress response controls the antiviral and apoptotic programs in dengue virus-infected dendritic cells. PLoS Pathog 2014;10:e1004566. 


\section{Cellular Physiology Cell Physiol Biochem 2018;47:1655-1666 \begin{tabular}{ll|l} 
DOI: 10.1159/000490984 & O 2018 The Author(s). Published by S. Karger AG, Basel \\
www.karger.com/cpb
\end{tabular}}

48 Zdunczyk Z, Drazbo A, Jankowski J, Juskiewicz J, Czech A, Antoszkiewicz Z: The effect of different dietary levels of vitamin $\mathrm{E}$ and selenium on antioxidant status and immunological markers in serum of laying hens. Pol J Vet Sci 2013;16:333-339.

49 Lee CY, Man-Fan Wan J: Vitamin E supplementation improves cell-mediated immunity and oxidative stress of Asian men and women. J Nutr 2000;130:2932-2937.

50 Meydani SN, Han SN, Wu D: Vitamin E and immune response in the aged: molecular mechanisms and clinical implications. Immunol Rev 2005;205:269-284.

51 Staeheli P, Puehler F, Schneider K, Gobel TW, Kaspers B: Cytokines of birds: conserved functions--a largely different look. J Interferon Cytokine Res 2001;21:993-1010.

-52 Susta L, Diel DG, Courtney S, Cardenas-Garcia S, Sundick RS, Miller PJ, Brown CC, Afonso CL: Expression of chicken interleukin-2 by a highly virulent strain of Newcastle disease virus leads to decreased systemic viral load but does not significantly affect mortality in chickens. Virol J 2015;12:122.

53 Sun Q, Shang Y, She R, Jiang T, Wang D, Ding Y, Yin J: Detection of intestinal intraepithelial lymphocytes, goblet cells and secretory IgA in the intestinal mucosa during Newcastle disease virus infection. Avian Pathol 2013;42:541-545.

54 Murakami AE, Sakamoto MI, Natali MR, Souza LM, Franco JR: Supplementation of glutamine and vitamin E on the morphometry of the intestinal mucosa in broiler chickens. Poult Sci 2007;86:488-495. 